\title{
Front Matter: Volume 9589
}

, "Front Matter: Volume 9589," Proc. SPIE 9589, X-Ray Lasers and Coherent X-Ray Sources: Development and Applications XI, 958901 (10 September 2015); doi: 10.1117/12.2219695

EDent: SPIE Optical Engineering + Applications, 2015, San Diego, California, United States 


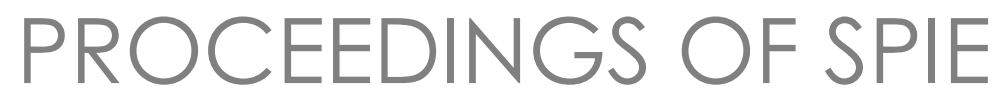

\title{
$X$-Ray Lasers and Coherent $X$-Ray Sources: Development and Applications XI
}

\author{
Annie Klisnick \\ Carmen S. Menoni \\ Editors
}

12-13 August 2015

San Diego, California, United States

Sponsored and Published by

SPIE 
The papers in this volume were part of the technical conference cited on the cover and title page. Papers were selected and subject to review by the editors and conference program committee. Some conference presentations may not be available for publication. Additional papers and presentation recordings may be available online in the SPIE Digital Library at SPIEDigitallibrary.org.

The papers reflect the work and thoughts of the authors and are published herein as submitted. The publisher is not responsible for the validity of the information or for any outcomes resulting from reliance thereon.

Please use the following format to cite material from these proceedings:

Author(s), "Title of Paper," in X-Ray Lasers and Coherent X-Ray Sources: Development and Applications XI, edited by Annie Klisnick, Carmen S. Menoni, Proceedings of SPIE Vol. 9589 (SPIE, Bellingham, WA, 2015) Six-digit Article CID Number.

ISSN: 0277-786X

ISSN: 1996-756X (electronic)

ISBN: 9781628417555

Published by

SPIE

P.O. Box 10, Bellingham, Washington 98227-0010 USA

Telephone +1 3606763290 (Pacific Time) · Fax +1 3606471445

SPIE.org

Copyright (c) 2015, Society of Photo-Optical Instrumentation Engineers.

Copying of material in this book for internal or personal use, or for the internal or personal use of specific clients, beyond the fair use provisions granted by the U.S. Copyright Law is authorized by SPIE subject to payment of copying fees. The Transactional Reporting Service base fee for this volume is $\$ 18.00$ per article (or portion thereof), which should be paid directly to the Copyright Clearance Center (CCC), 222 Rosewood Drive, Danvers, MA 01923. Payment may also be made electronically through CCC Online at copyright.com. Other copying for republication, resale, advertising or promotion, or any form of systematic or multiple reproduction of any material in this book is prohibited except with permission in writing from the publisher. The CCC fee code is $0277-786 \mathrm{X} / 15 / \$ 18.00$.

Printed in the United States of America.

Publication of record for individual papers is online in the SPIE Digital Library.

\section{SPIE. DIGITAL}

Paper Numbering: Proceedings of SPIE follow an e-First publication model. A unique citation identifier (CID) number is assigned to each article at the time of publication. Utilization of CIDs allows articles to be fully citable as soon as they are published online, and connects the same identifier to all online and print versions of the publication. SPIE uses a six-digit CID article numbering system structured as follows:

- The first four digits correspond to the SPIE volume number.

- The last two digits indicate publication order within the volume using a Base 36 numbering system employing both numerals and letters. These two-number sets start with 00, 01, 02, 03, 04, $05,06,07,08,09,0 A, 0 B \ldots$. OZ, followed by 10-1Z, 20-2Z, etc. The CID Number appears on each page of the manuscript. 


\title{
Contents
}

\author{
$\checkmark \quad$ Authors \\ vii Conference Committee \\ ix Introduction
}

\section{SESSION $1 \quad$ X-RAY INTERACTION WITH SOLIDS}

958902 Observation of dynamics and modification of solid surface using a picosecond soft $\mathbf{x}$-ray laser (Invited Paper) [9589-1]

958903 The application of extreme ultra-violet lasers in plasma heating and diagnosis [9589-2]

958904 Low electron temperature in ablating materials formed by picosecond soft $x$-ray laser pulses [9589-3]

958905 Soft $x$-ray laser ablation mass spectrometry for materials study and nanoscale chemical imaging [9589-4]

\section{SESSION 2 OPTICS FOR COHERENT SOURCES: JOINT SESSION WITH CONFERENCES 9588 AND 9589}

958907 Multilayer optics for coherent EUV/x-ray laser sources (Invited Paper) [9589-6]

\section{SESSION $3 \quad$ X-RAY INTERACTION WITH SOLIDS AND CLUSTERS}

$95890 \mathrm{~A}$ The observation of a transient surface morphology in the femtosecond laser ablation process by using the soft $x$-ray laser probe [9589-9]

9589 OC Generation of strongly coupled plasma using Argon-based capillary discharge lasers [9589-11]

\section{SESSION 4 SEEDED X-RAY LASERS}

9589 OE Modeling of dense injection-seeded Ni-like Krypton plasma amplifiers [9589-13]

9589 0G Chirped pulse amplification in x-ray free-electron lasers [9589-15]

SESSION 5 HIGH-REPETITION-RATE X-RAY LASERS AND APPLICATIONS

9589 OK X-ray characterization of short-pulse laser illuminated hydrogen storage alloys having very high performance [9589-19] 
$9589 \mathrm{OL}$ Employing partially coherent, compact gas-discharge sources for coherent diffractive imaging with extreme ultraviolet light [9589-20]

9589 OM 3D nanoscale imaging of biological samples with laboratory-based soft $x$-ray sources [9589-21]

\section{SESSION 6 BEAM PROPERTIES AND DIAGNOSTICS}

9589 ON Output beam polarisation of $x$-ray lasers with transient inversion (Invited Paper) [9589-22]

9589 OR Cross-correlation measurement of femtosecond hard x-ray pulses from a laser plasma source: approaching $100 \mathrm{fs}$ benchmark [9589-26]

\section{SESSION 7 HIGH-HARMONICS AND APPLICATIONS}

9589 OT The MEL-X project at the Lawrence Livermore National Laboratory: a mirror-based delay line for $\mathrm{X}$-rays [9589-28]

\section{SESSION 8 NEW X-RAY SOURCES}

$9589 \mathrm{OW}$ Attosecond pulse formation via switching of resonant interaction by tunnel ionization (Invited Paper) [9589-31]

9589 0X Using the XFEL to drive the gain of inner-shell X-ray lasers using photo-ionization and photoexcitation processes [9589-32]

\section{POSTER SESSION}

958910 Time-dependent simulation of the gas attenuator for the LCLS-II X-ray FEL's under high beam power operations [9589-35]

958911 Soft $x$-ray source based on the high-current capillary-discharge system [9589-36]

958912 Ultra-broadband ptychography with self-consistent coherence estimation from a high harmonic source [9589-37] 


\section{Authors}

Numbers in the index correspond to the last two digits of the six-digit citation identifier (CID) article numbering system used in Proceedings of SPIE. The first four digits reflect the volume number. Base 36 numbering is employed for the last two digits and indicates the order of articles within the volume. Numbers start with 00, 01, 02, 03, 04, 05, 06, 07, 08, 09, OA, OB...0Z, followed by 10-12, 20-2Z, etc.

Abe, Hiroshi, OK

Akhmedzhanov, T. R., OW

Alameda, Jennifer, OT

Anderson, E. H., 05

Antonov, V. A., OW

Aquila, Andy, OT

Aslanyan, Valentin, 03, 0C

Baba, Motoyoshi, OA

Baksh, P., 12

Bernstein, Elliot R., 05

Blechschmidt, Anne, OM

Boden, S. A., 12

Bourassin-Bouchet, Ch., 07

Boutet, Sébastien, OT

Bresenitz, R., OL

Brocklesby, W. S., OL, 12

Burian, Tomas, 05

Bußmann, J., OL

Carlton, D., 05

Chao, W., 05

Choukourov, Andrei, 11

Crick, Dean C., 05

Dacasa, Hugo, OG

Daido, Hiroyuki, OK

Decker, Todd, OT

Dehlinger, Aurélie, OM

Dehlinger, M., 07

Delmotte, F., 07

Depresseux, Adrien, OE

de Rossi, S., 07

Eyama, Takashi, OA

Faenov, Anatoly Y., 02, 04, OA

Fajardo, Marta, OG

Feng, Yiping, 10

Filevich, Jorge, 05

Frey, J. G., 12

Frolov, Oleksandr, 11

Furuyama, Takehiro, OK

Gautier, Julien, OE

Gröłzsch, Daniel, OM

Grützmacher, D., OL

Guillet, Serge, OT

Hasegawa, Nobory, 02, 04, 0A, ON

Hau-Riege, Stefan P., OT

Hill, Randy, OT

Idutsu, Rui, OA

ljaz, M., OR

Inogamov, Nail A., 02, 04, OA

labal, Mazhar, OR
Ishino, Masahiko, 02, 04

Ito, Atsushi M., 02, OA

Janulewicz, K. A., ON, OR

Jerome, A., 07

Juha, Libor, 05

Jung, Robert, OM

Juschkin, L., OL

Kakimoto, Naoya, OA

Kanngießer, Birgit, OM

Kawachi, Tetsuya, 02, 04, 0A, ON

Kim, C. M., ON

Kim, H., 12

Kocharovskaya, Olga, OW

Kolacek, Karel, 11

Krzywinski, Jacek, 10

Kuznetsov, llya, 05

Le, Thuy T. T., OG

Li, LU, OG

Mahieu, Benoît, OG

Maynard, Gilles, OE

Meltchakov, E., 07

Menoni, Carmen S., 05

Miao, Jianwei, OL

Minami, Yasuo, 02, OA

Nilsen, Joseph, OX

Nishikino, Masaharu, 02, 04, OA, ON

Nishimura, Akihiko, OK

Noh, D. Y., OR

Odstrčil, M., OL, 12

Ohnishi, Naofumi, 02, 0A

Ohshima, Takeshi, OK

Oliva, Eduardo, OE, OG

Ortiz, Eliazar, 10

Pardini, Tom, OT

Pikuz, Tatiana, 04

Radeonychev, Y. V., OW

Raubenheimer, Tor $\mathrm{O} ., 10$

Rocca, Jorge J., 05

Rossall, Andrew K., 03, 0C

Rowen, Michael, 10

Rudolf, D., OL

Sato, K., 02

Schafer, Donald W., 10

Schmidt, Jiri, 11

Sebban, Stéphane, OE

Seim, Christian, OM

Shahzad, Mohammed, 03

Shimomura, Takuya, OK

Shobu, Takahisa, OK 
Skobelev, Igor, 04

Soufli, Regina, 05, 0T

Stiel, Holger, OM, ON, OR

Straus, Jaroslav, 11

Suemoto, Tohru, 02, 0A

Takenaka, Yusuke, OK

Tallents, Gregory J., 03, 0C

Tissandier, Fabien, OE

Tokuhira, Shinnosuke, OK

Tomita, Takuro, OA

Uchida, Hirohisa, OK

Varnière, $\mathrm{F} ., 07$

Wilson, Sarah, 03, 0C

Woolston, M., 05

Yamagiwa, Mitsuru, 02, 04, 0A

Zeitoun, Philippe, OG

Proc. of SPIE Vol. 9589 958901-6

Downloaded From: https://www.spiedigitallibrary.org/conference-proceedings-of-spie on 26 Apr 2023 Terms of Use: https://www.spiedigitallibrary.org/terms-of-use 


\section{Conference Committee}

Program Track Chairs

Ali M. Khounsary, X-ray Optics, Inc. (United States) and Illinois Institute of Technology (United States)

Ralph B. James, Brookhaven National Laboratory (United States)

Conference Chairs

Annie Klisnick, CNRS, Université Paris-Sud 11 (France)

Carmen S. Menoni, Colorado State University (United States)

Conference Program Committee

Jens Biegert, ICFO - Institut de Ciències Fotòniques (Spain)

Hiroyuki Daido, Japan Atomic Energy Agency (Japan)

Yasin Ekinci, Paul Scherrer Institut (Switzerland)

Sylvie Jacquemot, Laboratorie pour l'Utilisation des Lasers Intenses (France)

Do-Kyeong Ko, Gwangju Institute of Science and Technology

(Korea, Republic of)

Michaela Kozlova, Institute of Physics of the ASCR, v.v.i.

(Czech Republic)

Ciaran L. S. Lewis, Queen's University Belfast (United Kingdom)

Stefan P. Moeller, SLAC National Accelerator Laboratory (United States)

Peter Viktor Nickles, Gwangju Institute of Science and Technology

(Korea, Republic of)

Joseph Nilsen, Lawrence Livermore National Laboratory

(United States)

Jorge J. Rocca, Colorado State University (United States)

Regina Soufli, Lawrence Livermore National Laboratory

(United States)

Szymon Suckewer, Princeton University (United States)

Gregory J. Tallents, The University of York (United Kingdom)

Alexander Vladimirovich Vinogradov, P.N. Lebedev Physical Institute (Russian Federation)

Marco Zangrando, Sincrotrone Trieste S.C.p.A. (Italy) 
Session Chairs

1 X-Ray Interaction with Solids

Annie Klisnick, CNRS, Université Paris-Sud 11 (France)

Joseph Nilsen, Lawrence Livermore National Laboratory

(United States)

2 Optics for Coherent Sources: Joint Session with Conferences 9588 and 9589

Carmen S. Menoni, Colorado State University (United States)

Ali M. Khounsary, X-ray Optics, Inc. (United States) and Illinois Institute of Technology (United States)

3 X-Ray Interaction with Solids and Clusters

Regina Soufli, Lawrence Livermore National Laboratory (United States)

Hiroyuki Daido, Japan Atomic Energy Agency (Japan)

4 Seeded X-Ray Lasers

Jorge J. Rocca, Colorado State University (United States)

Olga Kocharovskaya, Texas A\&M University (United States)

5 High-Repetition-Rate X-Ray Lasers and Applications

Chang Hee Nam, Gwangju Institute of Science and Technology

(Korea, Republic of)

Sylvie Jacquemot, Laboratorie pour I'Utilisation des Lasers Intenses

(France)

6 Beam Properties and Diagnostics

Larissa Juschkin, RWTH Aachen Universität (Germany)

Cristian Svetina, Elettra-Sincrotrone Trieste S.C.p.A. (Italy)

7 High-Harmonics and Applications

Gregory J. Tallents, The University of York (United Kingdom)

Eduardo Oliva, Universidad Politécnica de Madrid (Spain)

8 New X-Ray Sources

Annie Klisnick, CNRS, Université Paris-Sud 11 (France)

Carmen S. Menoni, Colorado State University (United States) 


\section{Introduction}

The X-ray Lasers and Coherent X-ray Sources: Development and Applications XI conference held in San Diego, California, 12-13 August 2015, attracted an international group of participants. Through invited and contributed talks they described the most recent developments in the generation and application of intense $x$-rays from plasma-based $x$-ray lasers, 4th generation accelerator-based sources and high-order harmonic $(\mathrm{HOH})$ generation. The unique and complimentary characteristics of these sources, in combination with novel optics and instrumentation, make possible new fundamental studies of x-ray laser/materials interactions and innovative applications in spectroscopies and imaging.

Work presented at the conference in plasma based $x$-ray lasers showed these table-top sources continue on their path to realize an average power nearing a milliwatt at sub-20 nm wavelengths and to extend emission down to $7.3 \mathrm{~nm}$ with substantially lower pump energies. Seeding of $x$-ray laser amplifiers with $\mathrm{HOH}$ was extensively discussed. Experiments and modeling showed prospects for achieving femtosecond pulse duration and extremely high peak brightness. Work on Free Electron Laser (FEL) sources reported fully coherent x-ray emission in the 20-100 eV range at Fermi@Elettra FEL, with the first implementation of a double-cascade seeding technique. $\mathrm{HOH}$ source development and their applications in the probing of molecular structure and ultrafast dynamics were also extensively covered. The conference program included a section on new $x$-ray sources where concepts that involve resonant XUV excitation of an atomic gas simultaneously irradiated by an IR laser field to generate attosecond pulses, the prospects of inner-shell x-ray lasers to achieve gain at higher photon energies than those demonstrated, and new scaling of high order harmonics from relativistic electron cusps were discussed. Essential to effectively use these $x$-ray sources in applications is complete diagnostics of the output beam. Novel concepts for the polarization of $x$-ray lasers, for the characterization of spatial coherence with Wigner distributions, and the understanding of the impact of partial temporal coherence on their spectral properties were presented.

The conference held a joint session on "Optics for Coherence Sources" with SPIE Conference 9588 Advances in X-Ray/EUV Optics and Components that was very well attended. The trends in multilayer optics are in developing broad band coatings capable to sustain ultrashort pulses. New processing methods enable the fabrication of high aspect ratio diffractive optics, which are needed in the x-ray regime.

Applications of coherent $x$-ray sources are now impacting more and newer scientific and technological areas. High resolution imaging techniques were discussed including ptychography, structural 3D imaging and composition imaging 
of biological samples. Recent progress in fundamental studies of interaction of intense $x$-ray pulses with solid materials were presented, including ablation of solid surfaces or generation of warm dense matter. Applications of ultrashort pulses to novel spectroscopies and ultrafast dynamics in gas phase and solids were also reported.

We gratefully acknowledge the continued support of SPIE for the field of x-ray lasers. We thank SPIE for the outstanding organization of the conference at all stages as well as the considerable efforts of the staff towards the publication of the Proceedings volume. We would like to thank the Programme Committee for their support and guidance and to the session chairs for their help in the running of the conference. Finally, we thank the many participants for their high quality scientific contributions to the 2015 meeting.

\section{Annie Klisnick Carmen S. Menoni}

